\title{
A brief review of anthrax in domestic animals
}

\author{
I. M. SMITH \\ M.Sc., Ph.D., M.R.C.V.S. \\ Department of Pathology, The Royal Veterinary College, University of London, London NW1 0TU
}

\begin{abstract}
Summary
Although there exists in the U.K. a high degree of control of industrial and agricultural anthrax in man and anthrax in animals originating either from animal products or from materials contaminated by contact with them, total control of anthrax in this country seems unlikely to follow until the disease is eliminated from livestock in the enzootic areas abroad. This view rests on the probability that any contamination of agricultural land by anthrax spores is unlikely to be permanent in Britain.
\end{abstract}

As anthrax is a zoonosis, its epidemiology is obviously of central interest. Very many species of animals can be infected with Bacillus anthracis, either naturally or experimentally. Although outbreaks of the disease in zoological gardens have been reported frequently and have involved species as diverse as ostriches and elephants, the precise natural susceptibility of most wild animals is largely unknown. What part they play, therefore, in the maintenance of the disease in the enzootic areas abroad is poorly understood. It may not, however, be large and there is little doubt that the most important source of the infection is in domestic herbivores. These species-cattle, sheep, horses and goats-appear to be the most susceptible to natural infection, whereas pigs and dogs, like man, can be infected only when exposed to relatively large numbers of spores. Infection in most domestic species arises chiefly by ingestion of the spore (Schlingman et al., 1956) but occasionally outbreaks, usually in horses, have arisen from mechanical transmission by biting insects (Sen \& Minett, 1944). Clinically and pathologically these cutaneous infections closely resemble malignant pustule in man. Generally, however, in the herbivorous domestic animals the disease is fulminating with few or no clinical signs and death occurs rapidly without premonitory indications. In the last few hours before death the herbivorous animals suffer a terminal septicaemia as a result of massive releases of capsulated bacilli from the lymphoid tissues, and especially the spleen. This rapid death within a day or two of infection with a massive septicaemia, which is easily detected microscopically provided putre- factive processes have not destroyed the bacilli, greatly simplifies diagnosis, provided always that the possibility of anthrax is kept in mind, as it usually is. Given that these carcases are properly handled and disposed of, little risk attaches to them, as will be noted shortly. The agricultural community in the U.K. are generally aware of anthrax and are legally obliged to notify any suspicious animals. The number of 'missed' cases which might constitute a human or veterinary hazard is, therefore, very small. By contrast with that in the domestic herbivores the disease in pigs in the U.K. differs in that these animals are relatively resistant and likely to survive for up to 14 days, suffering from a localized pharyngeal or intestinal form of the disease, which is non-septicaemic and can be diagnosed with certainty only by microscopical, cultural and biological methods after opening the carcase. Opening the carcase is a procedure that favours sporulation. Nonetheless, few cases of anthrax in man have ever been associated with handling infected pigs (Saunders, 1939) in such circumstances.

Anthrax is known in every country that possesses a livestock industry of any magnitude. There is no doubt, however, that the disease is most prevalent (Sterne, 1959) in those countries of tropical or subtropical latitudes (especially in the middle and far East and Africa) that practise a largely pastoral agriculture, the operations of which are only poorly subjected to veterinary control, so that the exact causes of deaths in free-ranging livestock are seldom known with any precision. For the same reason, application of the highly efficacious spore vaccines (Sterne, 1946) is less effective than it could be. Thus in these populations failure to diagnose and control anthrax leads to the creation of persistent foci of infection which can be scattered over wide areas. As carrion-eating species frequently open carcases in these areas before putrefaction has destroyed the vegetative organism (Minett, 1950) and as the rapidity of sporulation increases with increasing environmental temperature, these persistent foci constitute a continuous menace. These foci are most regularly found in areas with those dry soils that seriously lack microbial activity. Thus, spores frequently survive for 20 or more years. Un- 
TABLE 1. Mean number of anthrax incidents in U.K. in livestock*

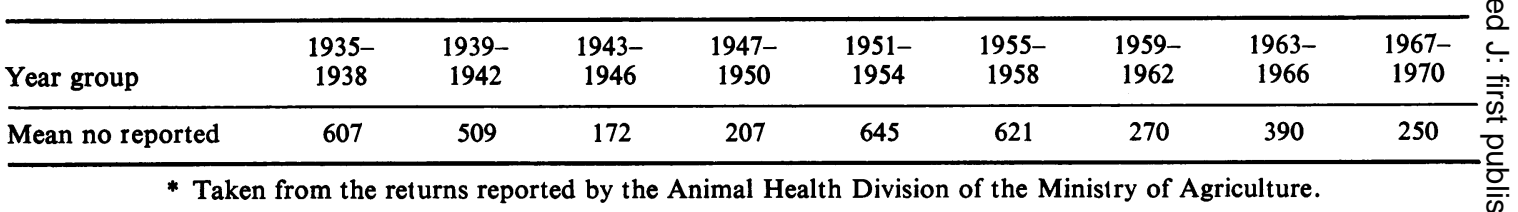

fortunately, it is this type of area which provides the preferred sources of sun-dried bones for industrial usage.

In countries of the more northerly latitudes, where environmental temperatures infrequently exceed about $20^{\circ} \mathrm{C}$, sporulation proceeds slowly in carcases and the bacilli are largely killed by putrefactive organisms before sporulation can proceed very far. Furthermore, the spore is unable to persist indefinitely in well-cultivated soils which possess considerable microbial activity; thus spore contamination of these soils generally disappears in 3 years or less (Sterne, 1959; Minett \& Dhanda, 1941). This lack of persistence partly accounts for the low prevalence of anthrax in man and animals in temperate latitudes. This being so, the complete control of anthrax in man and animals in the U.K. probably depends ultimately on elimination of the disease from tropical and subtropical latitudes, from which animal products-now mainly raw bones, hides and fleeces-are obtained.

As well as being a primary source of infection for man because of their use for industrial purposes, some of these possibly contaminated products (mainly, but not exclusively, bone meals) are incorporated into feeding stuffs, chiefly for the cattle and pig industries in this country. In a sense, therefore, cattle in the U.K. are used as a final and expensive monitoring system for the level of infection that prevails in these materials. It should be remembered that cattle or sheep (with the guinea-pig) are exquisitely susceptible to infection, as few as 1-10 spores being sufficient to produce the disease. It has repeatedly been demonstrated that the diminution or cessation of the employment of these few products (as happens in war-time) is accompanied by substantial decreases in the prevalence of anthrax in animals in northerly countries (Brennan, 1953). At present greater control of materials like bonemeals and their decreased use in animal feedstuffs have probably contributed to a fall in the prevalence of anthrax incidents in domestic animals in the U.K. in recent years (Table 1).
Whether complete control of the disease in the enzootic areas would result in its complete elimina-( tion in time from the U.K. is not certain, and $\vec{\circ}$ obviously depends largely on the probability of persistent foci in this country. Apart from some $\vec{\omega}$ localized areas, for example those which receive effluents from concentrations of tanneries, there is, as already pointed out, little likelihood that there are foci of spore-bearing, infective soils in the U.K.se though an instance is known where a completely untilled, acid soil has remained infective for manyis years after being heavily sown with spores. Broadly, however, the stringent control measures employedo for many years by the Animal Health Division of the Ministry of Agriculture under the terms of the Anthrax Order of the Diseases of Animals Acts haveo avoided any general risk of such situations. Virtuallyes without exception, therefore, all animal products $\overrightarrow{\overrightarrow{0}}$ originating in this country are gratifyingly free froun risk as a source of anthrax.

\section{References}

BrenNAN, A.D.J. (1953) Anthrax, with special reference to the recent outbreak of pigs. Veterinary Record, 65, 255.

MinETT, F.C. (1950) Sporulation and viability of Bacillus anthracis in relation to environmental temperature andō humidity. Journal of Comparative Pathology, 60, 161.

MinetT, F.C. \& Dhanda, M.R. (1941) Multiplication of Bacillus anthracis and Clostridium chauvoei in soil and in. water. Indian Journal of Veterinary Science, 11, 308.

SAUNDERS, J.E. (1939) Anthrax in swine. Veterinary Record 3 51, 1489.

Schlingman, A.S., Deviln, H.B., Wright, G.G., Maine R.J. \& MaNNING, M.C. (1956) Immunizing activity of alum-precipitated protective antigen of Bacillus anthracis 3 in cattle, sheep and swine. American Journal of Veterinary Research, 17, 256.

SEN, S.K. \& MinetT, F.C. (1944) Experiments on the trans mission of anthrax through flies. Indian Journal of Veterinary Research, 14, 149.

STERNE, M. (1946) Avirulent anthrax vaccine. Onderstepoort Journal of Veterinary Science, 21, 41.

STERNE, M. (1959) Anthrax. In: Infectious Diseases of Domestic Animals (Ed. by A. W. Stableforth and I. H.O Gallaway). Butterworths, London. 